Tiruvoipati Ravindranath (Orcid ID: 0000-0003-3800-902X)

Tiruvoipati Ravindranath (Orcid ID: 0000-0003-3800-902X)

Page | 1

\title{
Non-invasive ventilation of patients with acute asthma
}

Muhammad Sheikh, ${ }^{1,2}$

Ravindranath Tiruvoipati, ${ }^{1,3}$

James C Hurley, ${ }^{2}$

1. Intensive Care Research, Peninsula Health

2. Internal Medicine, Ballarat Health Services,

3. Monash University, Victoria Australia

Correspondence;

Professor Ravindranath Tiruvoipati

Consultant Intensivist and Director of Intensive Care Research, Peninsula Health

Director of Intensive Care, Peninsula Private Hospital

Adjunct Clinical Professor

Monash University, Melbourne, VIC

Email: travindranath@hotmail.com

P: +61 431279347 F: 0397847398

Acknowledgement: Dr Dora Pearce provided manuscript support.

Word count: abstract, 74; text; 1389; tables 1; figures 1; references; 13

Conflicts of interest: The authors declare that they have no conflict of interest.

Funding: None

\begin{abstract}
A retrospective observational study of 21 patients admitted to the Intensive Care Unit of Frankston Hospital with acute asthma between 2011 and 2014 was undertaken. We report the outcomes for three groups of patients; those that $\operatorname{did}(n=7)$ or $\operatorname{did}$ not $(n=6)$ receive initial therapy with non-invasive
\end{abstract}

This is the author manuscript accepted for publication and has undergone full peer review but has not been through the copyediting, typesetting, pagination and proofreading process, which may lead to differences between this version and the Version of Record. Please cite this article as doi: 10.1111/imj.14208

This article is protected by copyright. All rights reserved. 
ventilation (NIV) together with those that received invasive ventilation $(n=8)$. Patients successfully managed with NIV alone experienced a shorter ICU and hospital stay versus those who required invasive ventilation.

Key words;

Acute asthma, Non-invasive ventilation; length of stay. 


\section{Introduction}

There is recent interest in the use of non-invasive ventilation (NIV) as an alternative to intubation and invasive mechanical ventilation in select patients with severe acute asthma.

Non-invasive ventilation is commonly used for hypercapnic respiratory failure secondary to acute exacerbation of chronic obstructive pulmonary disease (COPD) in an effort to avoid invasive mechanical ventilation. A systematic review of 14 controlled trials in patients with COPD has shown that when compared with invasive ventilation, NIV results in significant reductions in mortality, complications, treatment failure, and length of hospital stay [1]. For example, within this systematic review of NIV versus usual care for exacerbations of COPD, NIV decreased hospital length of stay by an average of 3.2 days together with a near halving in incidence of mortality, need for intubation and complications of treatment [1].

Several reports have described the use of NIV in selected patients with respiratory failure due to exacerbations of asthma with promising results with respect to tolerability, length of stay and complications [2-9]. The use of NIV in moderate to severe exacerbations of asthma continues to be evaluated [8]. There is hope that a short trial of NIV may be a suitable option for carefully selected patients as it offers an approach to avoid intubation and invasive mechanical ventilation. Several studies suggest reduced mortality, hospital stay, and lowered risk of complications with NIV [4-9]. On the other hand, however, there is the risk of NIV failure in patients with severe cases of asthma [10]. Hence, the role of NIV in the management of asthma with respect to patient outcomes remains to be fully defined. The objective of this study is to describe the recent local experience of treating patients in ICU with acute severe asthma with versus without NIV and versus those treated with invasive ventilation in the context of a metropolitan hospital ICU.

\section{Materials and Methods}

\section{Participants and procedure}

This is a retrospective review of medical records of patients admitted to Frankston Hospital Intensive Care Unit (ICU) with a primary diagnosis of acute severe asthma between 2011 and 2014. This study was approved as a clinical audit under a Quality Assurance category by the Office for Research, Peninsula Health (QA reference number, QA/18/PH/14). 
The diagnosis of asthma was confirmed using clinical information and the results of lung function tests undertaken after the acute episode. Data was extracted from the ICU database, scanned medical records, Emergency Department notes, discharge summaries, and inpatient progress notes. Patients who required immediate intubation prior to ICU admission were excluded from this study. Patients were categorized in three groups on the basis of their initial therapy; those not requiring ventilation receiving medical therapy only, those who received NIV, and those who received invasive ventilation.

The acute asthma protocol in our ICU includes the use of nebulised or intravenous salbutamol, oral or intravenous prednisolone, and intravenous magnesium. Requirement for mechanical ventilation is based on meeting at least two of the following criteria: severe breathlessness at rest, respiratory rate $>30, \mathrm{PaO}_{2}<60 \mathrm{mmHg}$ (on room air) or $<80 \mathrm{mmHg}$ on supplemental oxygen, $\mathrm{PaCO}_{2}$ e 50mmHg, $\mathrm{pH} \mathrm{d7.30,} \mathrm{and/or} \mathrm{use} \mathrm{of} \mathrm{accessory} \mathrm{muscles} \mathrm{of} \mathrm{respiration.} \mathrm{The} \mathrm{criteria} \mathrm{for} \mathrm{failing}$ NIV was as follows; worsening haemodynamic status, deteriorating arterial blood gases (ABG) test results, face mask intolerance, or appearances of any of the indications for intubation, or on request. Patients meeting the criteria for failing NIV were subsequently invasively ventilated. NIV was available in two forms: bi-level (Bi-PAP) and continuous positive airway pressure (CPAP). The mode of NIV administered was at the discretion of the attending doctor.

The major outcome for each group was the length of stay in the ICU and hospital stay overall. The following complications were recorded: ventilator-associated pneumonia, delirium, nosocomial infections, barotrauma, muscle weakness, hyperkalaemia, acute kidney injury and mortality.

\section{Results}

Over the 3-year period, 21 patients with acute exacerbation of asthma requiring admission to the ICU met the eligibility criteria for this study. The age, the proportion of smokers and the baseline vital signs was similar among the three patient groups (Table 1). However, the mean arterial $\mathrm{pH}$ was lower in the group that received invasive ventilation.

Six patients did not require ventilation, seven received only NIV and eight required invasive ventilation during their ICU stay. Of those receiving invasive ventilation, in five this occurred after failing NIV and in three this occurred after failing medical therapy. The baseline patient 
characteristics were similar for the three groups for all parameters with the exception of arterial blood $\mathrm{pH}$, which was lowest in the group requiring invasive ventilation.

The major indication for switching from NIV to invasive ventilation were a worsening haemodynamic status or a deteriorating arterial blood gases test results. The patients requiring switch had an average $\mathrm{pH}$ of 7.20 and lactate levels of $2.2 \mathrm{mmol} / \mathrm{L}$.

The ICU length of stay was less than three days for all patients receiving only medical therapy. By contrast, the ICU length of stay for those patient that required NIV and invasive ventilation was $3.3 \pm 2.6$ and $5.8 \pm 5.5$ days (mean $\pm \mathrm{SD}$; $<<0.05$ ), respectively (Figure 1). The overall hospital length of stay was $5.9 \pm 3.9$ and $8.1 \pm 5.5$ days (mean $\pm \mathrm{SD} ; \mathrm{p}<0.05$ ) for those patient that required NIV and invasive ventilation, respectively.

There were three complications in the invasive group; ventilator associated pneumonia, hyperkalaemia and acute kidney injury. There was one complication in NIV group, being hospital acquired pneumonia. There were no complications in the medical therapy only group. None of the patients in this study died in hospital.

\section{Discussion}

This study reports outcomes among patients admitted to ICU with acute severe asthma. We describe patient outcomes for three categories of patients; those receiving medical therapy alone, those receiving NIV alone, and those who received invasive ventilation. Patients in the medicationonly group spent the shortest time in the ICU, as might be expected. The length of ICU stay was longest for those who required invasive ventilation and intermediate for patients who received NIV. The overall hospital length of stay showed the same ranking among the three groups. For each of the average ICU and the hospital length of stay, the differences across the three groups were statistically significant.

The ICU and hospital lengths of stay found in this study are comparable to other reports in the literature for this patient group. Moreover, patients receiving NIV have lengths of stay for both ICU and overall hospital that is typically between one and two days shorter versus patients receiving invasive ventilation in studies where this has been compared [6,7,11]. 
The incidence of complications in this small study was slightly lower amongst the two patient groups that were not invasively ventilated versus those that were, as is the general experience [1]. There was an acceptable conversion to invasive ventilation from patients initially treated with either medical therapy alone or with NIV amongst this high severity ICU admitted population. The rates of complications reported here are broadly similar to that reported elsewhere [2-9].

Furthermore, even though NIV appears to be a first line therapy for the majority of patients with severe asthma requiring ICU admission, some of the patients invasively ventilated had initially been managed with medications only (37.5\%) or with NIV (62.5\%). The reasons for switching from NIV to invasive ventilation were mostly in response to clinical decline such as with increasing lactate levels or respiratory acidosis. It is important to note that while NIV has shown preferable outcomes for some patients to invasive ventilation, it may not be appropriate for all cases of severe asthma patients presenting to the ED. However, there is a need for further studies to explore predictors of NIV failure in acute severe asthma that have clinical relevance in determining optimal care for these patients [10].

Several limitations of this observational study limit the generalizability of the results. The study was small, single center, retrospective, and there were imbalances in measures of asthma severity among the three groups. The study was undertaken within a metropolitan hospital ICU. A further acknowledged limitation it that the focus of this study was un-intubated patients admitted to the ICU with acute asthma. As patients intubated in the emergency department were excluded, it is difficult to comment on the role of NIV in the pre-ICU setting. Hence, despite the statistical significance of the findings, these findings are merely descriptive and hence they need to be interpreted with caution. Nevertheless, our results are consistent with the published literature from Australia and New Zealand $[8,11,12]$. Non-invasive ventilation may be used in acute asthma, but caution is needed and close observation in a high-dependency or ICU is recommended [13].

\section{Conclusion}

This study reports the recent experience in the management of patients with acute severe asthma who were successfully managed with non-invasive ventilation without a need for escalation to invasive ventilation within a metropolitan hospital ICU. These patients experienced shorter ICU and hospital stays versus those who require invasive ventilation with possibly fewer complications. 


\section{References}

1. Ram FS, Picot J, Lightowler J, Wedzicha JA. Non-invasive positive pressure ventilation for treatment of respiratory failure due to exacerbations of chronic obstructive pulmonary disease. Cochrane Database Syst Rev. 2004;(1):CD004104. 10.1002/14651858.CD004104.pub2

2. Soroksky A, Stav D, Shpirer I. A pilot prospective, randomized, placebo-controlled trial of bilevel positive airway pressure in acute asthmatic attack. Chest. 2003;123:1018-1025.

3. Teke T, Yavsan M, Uzun K. Non-invasive ventilation for severe acute asthmatic attacks. $J$ Academic Emerg Med. 2015;14:30-34

4. Corrêa TD, Sanches PR, Morais LC, Scarin FC, Silva E, Barbas CS. Performance of noninvasive ventilation in acute respiratory failure in critically ill patients: a prospective, observational, cohort study. BMC Pulmon Med. 2015;15(1):144.

5. Fernandez MM, Villagra A, Blanch L, Fernandez R. Non-invasive mechanical ventilation in status asthmaticus. Intensive Care Medicine. 2001;27(3):486-492.

6. Murase K, Tomii K, Chin K, Tsuboi T, Sakurai A, Tachikawa R, et al. The use of noninvasive ventilation for life-threatening asthma attacks: Changes in the need for intubation. Respirology 2010; 15: 714-20.

7. Meduri GU, Cook TR, Turner RE, Cohen M, Leeper KV. Non-invasive positive pressure ventilation in status asthmaticus. Chest. 1996;110:767-774.

8. Pallin M, Hew M, Naughton MT. Is non-invasive ventilation safe in acute severe asthma? Respirology. 2015;20(2):251-257

9. Green E, Jain P, Bernoth M. Non-invasive ventilation for acute exacerbations of asthma: A systematic review of the literature. Australian Crit Care. 2017; 30:289-97.

10. Meeder AM, Tjan DHT, van Zanten ARH. Noninvasive and invasive positive pressure ventilation for acute respiratory failure in critically ill patients: a comparative cohort study. Journal of Thoracic Disease. 2016;8(5):813-825.

11. Stow PJ, Pilcher D, Wilson J, George C, Bailey M, Higlett T, Bellomo R, Hart GK; Australian \& New Zealand Intensive Care Society Adult Patient Database Management Committee. Improved outcomes from acute severe asthma in Australian intensive care units (1996 2003). Thorax. 2007;62(10):842-7. 
12. Pallin M, Naughton MT. Noninvasive ventilation in acute asthma. J Crit Care. 2014;29(4):586-93.

13. Non-invasive ventilation. In; Therapeutic guidelines: Respiratory. Version 5. Melbourne: Therapeutic Guidelines Limited; 2014. 
Table 1. Baseline patient characteristics

\begin{tabular}{lllll}
\hline & $\begin{array}{l}\text { Medical } \\
\text { therapy alone } \\
\mathbf{n}=\mathbf{6}\end{array}$ & $\mathbf{N I V}$ & $\begin{array}{l}\text { Invasive } \\
\text { ventilation }\end{array}$ & $\boldsymbol{p}^{\dagger}$ \\
& $29.2 \pm 6.4$ & $31.8 \pm 8.1$ & $40.5 \pm 13.6$ & 0.12 \\
& $3 / 3$ & $1 / 6$ & $3 / 5$ & NA \\
\hline $\begin{array}{l}\text { Age (years) } \\
\text { Male/Female (n) }\end{array}$ & 4 & 3 & 6 & NS \\
$\begin{array}{l}\text { History of smoking (n) } \\
\text { Vital signs }\end{array}$ & $133 \pm 34$ & $125 \pm 30$ & $122 \pm 19$ & 0.80 \\
$\begin{array}{l}\text { Pulse rate (beats/min) } \\
\text { Respiratory rate }\end{array}$ & $29 \pm 6$ & $39 \pm 14$ & $31 \pm 9$ & 0.21 \\
$\quad$ (breaths/min) & $136 \pm 17$ & $137 \pm 8$ & $140 \pm 19$ & 0.91 \\
$\begin{array}{l}\text { SBP (mmHg) } \\
\text { MAP (mmHg) }\end{array}$ & $110 \pm 6$ & $101 \pm 10$ & $111 \pm 11$ & 0.33 \\
arterial pH & $7.40 \pm 0.04$ & $7.43 \pm 0.06$ & $7.20 \pm 0.20$ & 0.02 \\
\hline
\end{tabular}

Data are mean \pm standard deviation, unless otherwise stated.

${ }^{\dagger}$ Comparisons between invasive versus other treatment groups were undertaken using Fisher's exact test for categorical data and a t-test for continuous data.

$\mathrm{NIV}=$ non-invasive ventilation

$\mathrm{NS}=$ non-significant; NA $=$ Not applicable

$\mathrm{SBP}=$ systolic blood pressure; MAP $=$ Mean arterial pressure. 
Figure 1. ICU length of stay (LOS) for patients requiring NIV (NIV + Medications), invasive ventilation (Invasive) or medical therapy alone (Medications). The test of equality (non-parametric log-rank test $)$ of survivor functions for ICU LOS is Ç2(2) $=11.56(\mathrm{p}=0.0031)$.

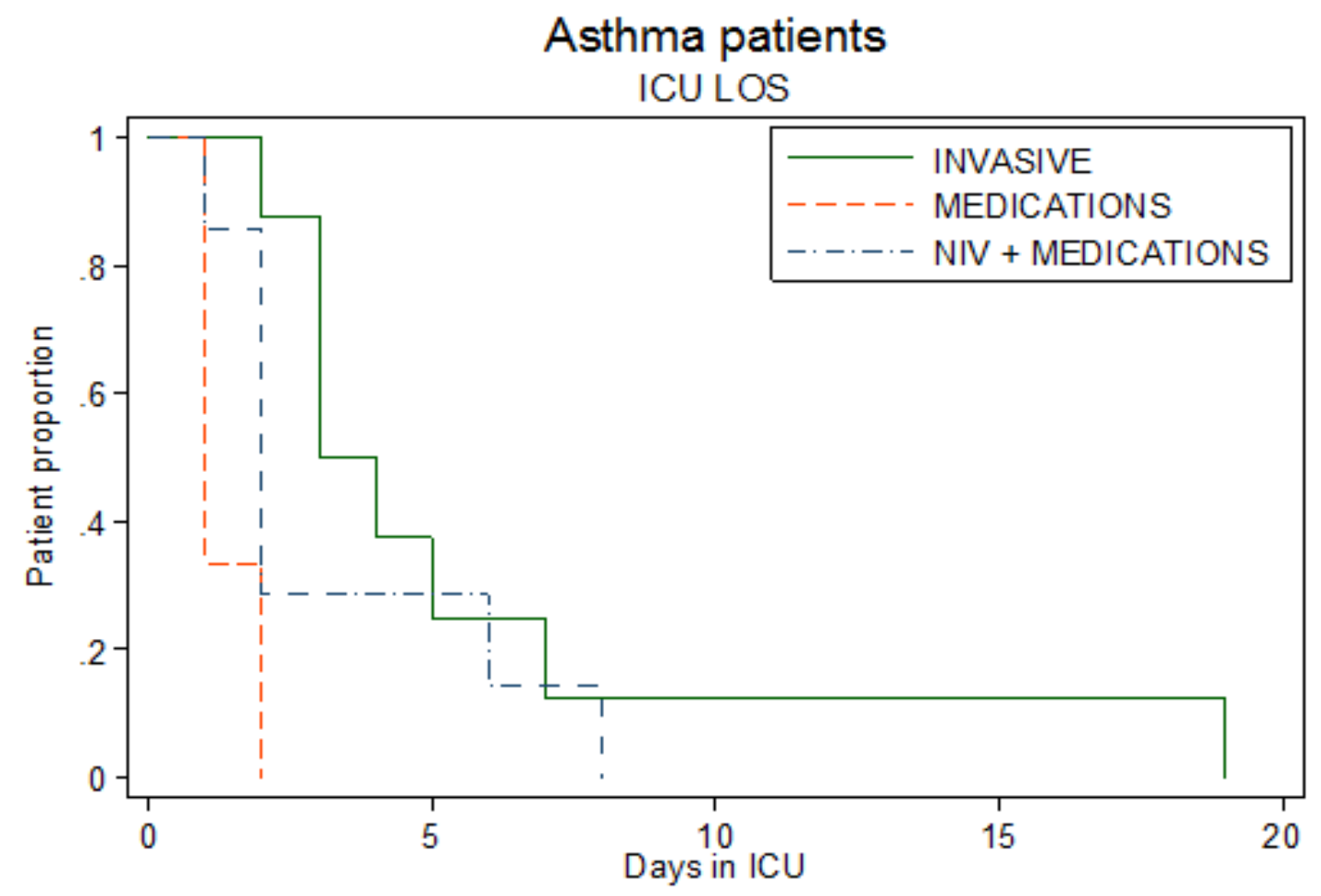

This article is protected by copyright. All rights reserved. 


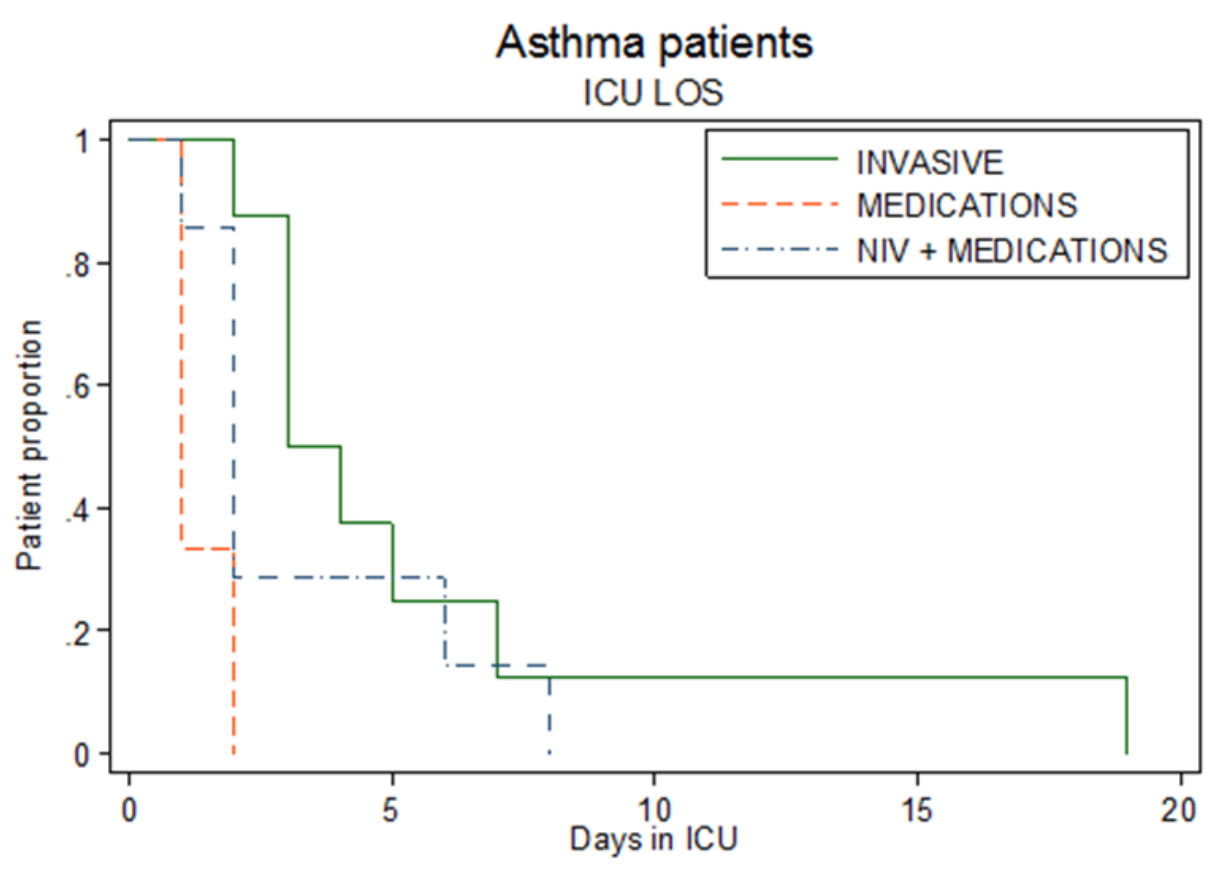

This article is protected by copyright. All rights reserved. 


\section{University Library}

\section{- M M I N E R VA A gateway to Melbourne's research publications}

Minerva Access is the Institutional Repository of The University of Melbourne

\section{Author/s:}

Sheikh, M;Tiruvoipati, R;Hurley, JC

Title:

Non-invasive ventilation of patients with acute asthma

\section{Date:}

2019-02-01

Citation:

Sheikh, M., Tiruvoipati, R. \& Hurley, J. C. (2019). Non-invasive ventilation of patients with acute asthma. INTERNAL MEDICINE JOURNAL, 49 (2), pp.262-264. https://doi.org/10.1111/ imj. 14208.

Persistent Link:

http://hdl.handle.net/11343/285400 